\title{
Isolation and Characterization of Cellulose Whiskers from Kenaf (Hibiscus cannabinus L.) Bast Fibers
}

\author{
Lukmanul Hakim Zaini ${ }^{1}$, Mehdi Jonoobi ${ }^{2,3}$, Paridah Md. Tahir ${ }^{1,4^{*}}$, Samaneh Karimi ${ }^{1}$ \\ ${ }^{1}$ Laboratory of Biocomposite Technology, Institute Tropical Forestry and Forest Products (INTROP), Universiti Putra Malaysia, \\ Serdang, Malaysia; ${ }^{2}$ Department of Engineering Science and Mathematics, Lulea University of Technology, Lulea, Sweden; ${ }^{3}$ Faculty \\ of Natural Resources, Sari Agricultural Sciences and Natural Resources University, Sari, Iran; ${ }^{4}$ Faculty of Forestry, Universiti Putra \\ Malaysia, Serdang, Malaysia. \\ Email: *parida_introb@yahoo.com
}

Received October $10^{\text {th }}, 2012$; revised November $30^{\text {th }}, 2012$; accepted December $15^{\text {th }}, 2012$

\begin{abstract}
Cellulose whiskers were isolated from kenaf (Hibiscus cannabinus L.) bast fibers via sulfuric acid and hydrochloric acid hydrolysis. Raw kenaf bast, $\mathrm{NaOH}$ treated, bleached fibers, sulfuric acid whiskers (SAW) and hydrochloric acid whiskers (HClW) morphology, functional groups, crystallinity, and thermal stability were characterized. The TEM images showed that the sulfuric acid and $\mathrm{HCl}$ whiskers have average diameters and length range of $3 \mathrm{~nm}$ and $100-500 \mathrm{~nm}$, respectively. The FTIR study indicated that during the conversion process, most of the hemicellulose and almost all the lignin were removed by the $\mathrm{NaOH}$ and subsequent bleaching treatments. The crystallinity of $\mathrm{HCl}$ whiskers was found to be higher $(84 \%)$ than that of sulfuric acid whiskers $(72 \%)$. Thermogravimetric analysis indicated that $\mathrm{HCl}$ whiskers had better thermal stability than the sulfuric acid ones. In addition, a two-stage decomposition behavior was revealed by TGA in the sulfuric acid whiskers because of incorporation of the sulfate group with the cellulose crystals.
\end{abstract}

Keywords: Cellulose Whiskers; Kenaf; Bast Fibers; Crystallinity

\section{Introduction}

Cellulose is the most abundant biorenewable material on earth. It is an infinite source of raw material for environmentally-friendly and biocompatible products [1]. The yearly biomass production of cellulose has been estimated at about 1.5 trillion tons [1]. The growing global interest in renewable resources and environmentallycompatible materials has brought a considerable scientific and technological research in the field of cellulose. In plants, cellulose is present as whisker-like microfibrils. It is biosynthesized and deposited either in a continuous manner whereby it is arranged in highly linear and parallel manner, i.e., crystalline region, or in a loose and lowordered orientation, i.e. amorphous region [2].

The crystalline region of microfibrils, called cellulose whiskers, is almost defect-free, with the consequence of axial physical properties of cellulose biogenesis approaching those of perfect crystals [3]. These whiskers have high modulus and act as efficient reinforcing materials because of their perfect crystalline arrangement [2]. This characteristic was proven by Aji et al. [4] who concluded that cellulose whiskers had better crystallinity than the microfibers. When such materials are used to produce

${ }^{*}$ Corresponding author. composites they create high-performance nanocomposites that exhibit outstanding properties. This reinforcing capability results from the intrinsic chemical nature of cellulose and from its hierarchical structure. However, lignocellulosic fillers are used only to a limited extent in industrial applications due to difficulties associated with surface interactions [5].

The advancement in nanotechnology has brought about a trend in isolating whiskers from various cellulose sources such as ramie [6], grass fiber [7], sisal [8], and Tunicin [9]. Azizi Samir et al. [5] described whiskers as formation of high-purity single crystals that have been formed by nanofibers under controlled conditions. These pure crystals have high aspect ratios and surface areas which render polymer matrices high reinforcing capabilities [10-12]. The conversion of their molecular arrangements into highly ordered structure not only imparts high strengths to the material but also enhances its electrical, optical, magnetic, ferromagnetic, dielectric properties.

Acid hydrolysis can be used to isolate cellulose whiskers. It is a simple process which can be carried out using different type of acid and combinations of concentration, time and temperature $[8,13,14]$. The amorphous part of cellulose more susceptible undergoes acidic hydrolysis compared to crystalline part. Nevertheless, the crystalline 
part can be smoothly hydrolyzed by concentrated acids such as concentrated sulfuric acid and supersaturated hydrochloric acid [15]. Molecular degradation in cellulose take place by attack of the $\beta$-1,4-glucosidic linkage which is susceptible to acid-catalyzed hydrolysis [16]. The hydrolysis process depends on the interaction conditions, such as the nature and concentration of the acid, the reaction temperature, and processing duration [16]. Both hydrochloric and sulfuric acids are superior in their abilities to hydrolyze $\beta$-1,4-glucosidic bonds due to its lower acid dissociation constant. The acid dissociation constant (pKa) is a quantitative measure of the strength of an acid in solution. The larger the value of $\mathrm{pKa}$, the smaller is the extent of dissociation, and vice versa. According to Krassig [16], the mechanism of the acidcatalyzed hydrolysis of cellulose proceeds in three stages. Firstly, rapid protonation of the glycosidic oxygen atom takes place. Secondly, a slow transfer of the positive charge to $C(1)$ occurs, leading to a cyclic carbonium cation production and to a simultaneous split of the glycosidic linkage. Thirdly, quick addition of water to the carbonium ion takes effect.

Previously studies highlighted a potential for kenaf fiber to act as filler or reinforcement agent in biocomposites [17-19]. Kenaf (Hibiscus cannabinus L.) consists of two separate parts known as bast and core. The bast is the outer section of the plant stem while the core is its inner part [20]. Kenaf bast fibers have been found to be possessing attractive mechanical properties that entitle them to be used as reinforcements in polymer composites [21-23] and as an alternative to glass fibers and aramid. Jonoobi et al. [24] reported that the kenaf bast fibers have a cellulose content of $63.5 \%$, which is within the range reported by Mohanty et al. [25].

As stated above, numerous studies have investigated the isolation and properties of cellulose whiskers. Based on our knowledge very little information has been reported on characterization of cellulose whiskers from kenaf bast. Therefore, the main objective of this work was to isolate cellulose whiskers from kenaf bast fibers by acid hydrolysis and to characterize their properties. The influence of different solvents on the morphology, crystallinity, and thermal stability of the resulting whiskers were also evaluated.

\section{Experimental}

\subsection{Materials}

Four-month old kenaf stems of variety 36 were obtained from the experimental plot of the National Kenaf and Tobacco (NKTB) Company, Malaysia. Sulfuric acid (95\%), chloroform, and $\mathrm{HCl}(37 \%)$ were purchased from Aldrich while sodium chlorite and sodium hydroxide were supplied by RND I-Tech Sdn., Malaysia. The har- vested kenaf stems were peeled to separate the outer part (bast) from the inner part (core). The bast was then dried in an industrial oven to a moisture content of $9.8 \%$.

\subsection{Whiskers Isolation}

The whiskers were isolated from kenaf bast fibers following the method of Siquera et al. [11].

Kenaf bast was ground to $0.25 \mathrm{~mm}$ size by FRITSCH universal cutting mill pulverisette and treated with $4 \%$ $(\mathrm{w} / \mathrm{w}) \mathrm{NaOH}$ solution at $80^{\circ} \mathrm{C}$ for 2 hours. This treatment was repeated 3 times. After each treatment, fibers were filtered and washed with distilled water until the alkali was completely removed. A subsequent bleaching treatment of the fibers using the same amount of acetate buffer, aqueous chlorite $(1.7 \% \mathrm{w} / \mathrm{w})$, and distilled water was applied in order to bleach the fibers. The bleaching treatment was carried out four times at $80^{\circ} \mathrm{C}$ for 2 hours (each treatment) under mechanical stirring. Acid hydrolysis was performed by subjecting $4 \%-6 \%(\mathrm{w} / \mathrm{w})$ bleached kenaf bast pulp into pre-heated $65 \%(\mathrm{v} / \mathrm{v})$ sulfuric acid at a temperature of $50^{\circ} \mathrm{C}$ for $60 \mathrm{~min}$. The suspension was constantly mixed using magnetic stirrer. Then, the hydrolyzed pulp was centrifuged at $4000 \mathrm{rpm}$ for $30 \mathrm{~min}$ and dialyzed in distillated water. Subsequently, the whiskers suspension was homogenized by using an Ultra Turax T25 homogenizer for $5 \mathrm{~min}$. Some drops of chloroform were added as protectant to the whiskers suspension which was stored at $4^{\circ} \mathrm{C}$.

The second hydrolysis treatment was conducted using $\mathrm{HCl}$ as described by Braun et al. [26]. Bleached fibers were preblended with distilled water $(1: 20(\mathrm{w} / \mathrm{v}))$ using laboratory blender for $10 \mathrm{~min}$. Then, the slurry was soaked overnight. Hydrochloric acid was added to the slurry until $2.5 \mathrm{M}$ acid strength was achieved. The sample was preheated at $105^{\circ} \mathrm{C}$ and stirred before acid addition. The hydrolysis was carried out for 20 min with stirring. After hydrolysis, the process was the same as Siquera's methodology described above.

\subsection{Scanning Electron Microscopy (SEM)}

Scanning electron microscopy (SEM) analysis was performed using a Jeol JSM 7600F Scanning Electron Microscope. Glimmer plates were fixed with conducting carbon on a specimen holder and then a drop of diluted fibril (raw kenaf bast, $\mathrm{NaOH}$ treated, or bleached fibers)/ water suspension $(1: 20 \mathrm{w} / \mathrm{v})$ was put onto it. The samples were air-dried and the remaining fibrils were sputtered with a platinum layer about $5 \mathrm{~nm}$ thick. The images were taken with an accelerating voltage of $2 \mathrm{kV}$ and 100 fibers diameter was measured.

\subsection{Transmission Electron Microscopy (TEM)}

The size and shape of whiskers were studied using a 
transmission electron microscope Hitachi model H-7100. A drop of diluted kenaf whiskers suspension was deposited on the carbon-coated grids and allowed to dry at room temperature. The grid was stained with a $0.5 \%$ solution of uranyl acetate and dried at room temperature. Measurement of 150 fibers diameter were carried out using an image analyzer program, XL Docu.

\subsection{Fourier Transform Infrared Spectroscopy (FTIR)}

A Fourier transform infrared spectroscopy (FTIR) study was done using Perkin-Elmer spectrometer 100. Prior to this analysis, all fibers were ground to a diameter of about $100 \mu \mathrm{m}$ and then mixed with $\mathrm{KBr}$ to prepare homogeneous suspensions and afterwards pressed into transparent pellets and analyzed in transmittance mode within the range of $4000-500 \mathrm{~cm}^{-1}$.

\subsection{X-Ray Diffraction}

Structural and phase analyses of the samples were implemented using an X-ray diffractometer (Philips $\mathrm{P}$ W 3040/60 X'pert Pro) with CuK $\alpha$ radiation (wavelength of $1.5405 \AA)$ and step-scan mode $\left(2 \theta\right.$ range: $\left.5^{\circ}-60^{\circ}\right)$. The crystalline index of cellulose, $\mathrm{C}_{\mathrm{Ir}}$, was calculated using the following equation [27]:

$$
\mathrm{C}_{\mathrm{Ir}}(\%)=\left[\left(\mathrm{I}_{002}-\mathrm{I}_{\mathrm{am}}\right) / \mathrm{I}_{002}\right] \times 100
$$

where $I_{002}$ is the intensity of lattice peak diffraction and $\mathrm{I}_{\mathrm{am}}$ is the peak intensity of the amorphous fraction. A diffraction angle of around $2 \theta=22.5^{\circ}$ was peak for plane (002) and the lowest intensity at a diffraction angle of around $2 \theta=18.0^{\circ}$ was measured as the amorphous part.

\subsection{Thermogravimetric Analysis (TGA)}

Thermal stability data was obtained using the TGA/ SDTA 851 (Mettler Toledo) thermogravimetric analyzer under linear temperature conditions. The samples were heated in platinum crucibles within the temperature range $35^{\circ} \mathrm{C}-600^{\circ} \mathrm{C}$ at a rate of $10^{\circ} \mathrm{C} / \mathrm{min}$ in a nitrogen atmosphere.

\section{Results and Discussion}

\subsection{Microscopic Analysis}

The isolation of whiskers from kenaf bast is a multistep process which involves chemical treatments. Firstly, the fibers should be separated from their cell walls in order to be able to study the properties of this nanomaterial. Proper chemical treatment to obtain the whiskers without damaging the fibers is needed.

Figure 1 shows SEM images in each of the three stages of fiber treatment. The images show the effects of
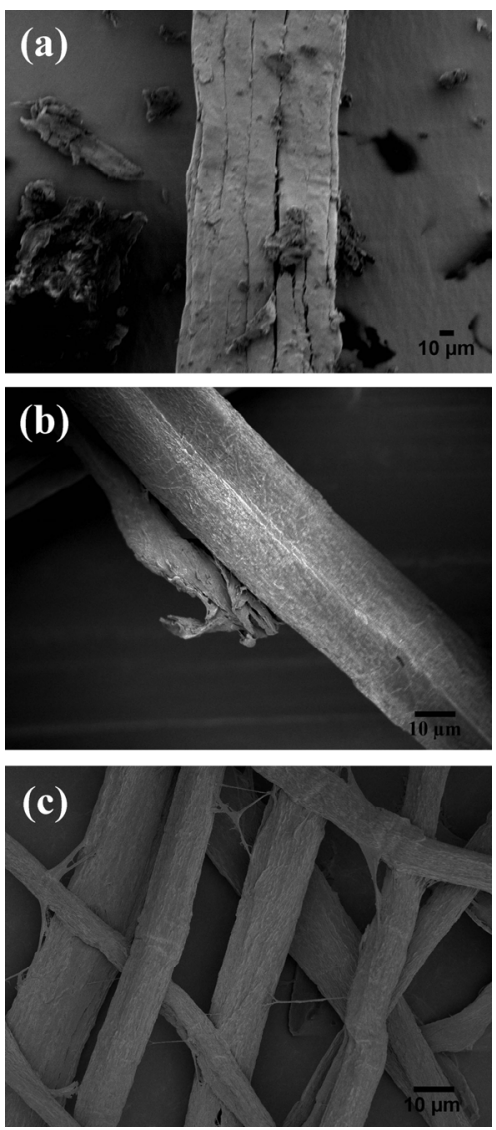

Figure 1. Scanning electron micrographs of (a) raw bast; (b) NaOH treatment; (c) after bleaching.

chemical treatments on the morphology of kenaf bast fibers. Figure 1(a) shows the raw kenaf fiber bundles which consist of individual fibers bonded by lignin. The image analysis revealed that the diameters of the raw kenaf fibers were around $100 \mu \mathrm{m}$. In Figure 1(b), it can be seen that the $\mathrm{NaOH}$-treated kenaf fibers had smaller diameters than those observed in Figure 1(a). After $\mathrm{NaOH}$ treatment, the fiber diameters ranged from $20-90$ $\mu \mathrm{m}$. The mechanical grinding that was applied before chemical treatment led to these wide variations in fiber diameters. As the result, the $\mathrm{NaOH}$ treatment did not affect the fiber surface consistently. However, the bleaching treatment broke most of the lignin bonds in the fibers after $\mathrm{NaOH}$ treatment sequence. Consequently, the individual fibers showed smooth surface as can be seen in Figure 1(c). After the samples were bleached, the fiber diameters reduced to an average value of $11 \pm 3 \mu \mathrm{m}$.

Figure 2 illustrates how the different hydrolysis methods affect the isolation of whiskers. Both images show whiskers with a needle-like structure. The tendency to agglomerate can also be observed in both images. This tendency can be attributed to the drying conditions during sample preparation which involved evaporation of water. 

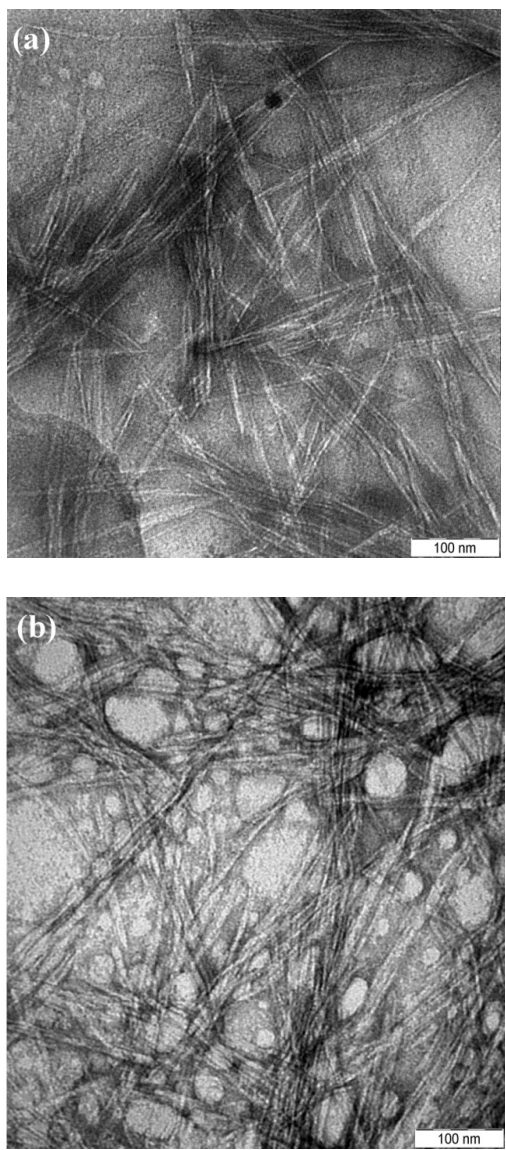

Figure 2. Transmission electron micrographs of kenaf bast whiskers hydrolyzed using; (a) sulfuric acid; (b) HCl under the same magnification $(50,000 \times)$.
Figure 3 shows the diameter distribution of whiskers extracted by sulfuric acid and $\mathrm{HCl}$ hydrolysis. Diameter of both whiskers was calculated based on measurement of 150 individual whiskers. As can be seen in Figure 3(a), the diameters of the sulfuric acid whiskers ranged from $2-5 \mathrm{~nm}$ and most of these whiskers had diameters ranging from 2 to $4 \mathrm{~nm}$. The $\mathrm{HCl}$ whiskers had wider diameters, ranging from 2 to $6 \mathrm{~nm}$ (Figure 3(b)) and most of the samples had diameters within the range of 2 to $4 \mathrm{~nm}$. However, there were also whiskers with relatively diameters ranging from 4 to $5 \mathrm{~nm}$. The average diameters of the sulfuric acid and $\mathrm{HCl}$ whiskers were quite similar; around $3 \mathrm{~nm}$.

In fact, the aspect ratio of whiskers is an important property that describes their reinforcing abilities. Hundred of each sulfuric acid and $\mathrm{HCl}$ whiskers were observed for length measurement. The range of lengths for both whiskers was $100-500 \mathrm{~nm}$. However, the average lengths of the sulfuric acid and $\mathrm{HCl}$ whiskers were $330 \pm$ $66 \mathrm{~nm}$ and $224 \pm 76 \mathrm{~nm}$, respectively. Based on the length and diameter measurements, the aspect ratios of the sulfuric acid and $\mathrm{HCl}$ whiskers were 109 and 64, respectively. This suggests that sulfuric acid whiskers are better than the $\mathrm{HCl}$ whiskers. Based on this result, a higher reinforcing capability is expected for the sulfuric acid, rather than the $\mathrm{HCl}$, whiskers.

The above mentioned whisker diameters compare with the diameters had been reported for whiskers extracted from kenaf bast fiber; $12 \pm 3 \mathrm{~nm}, 7$ - $84 \mathrm{~nm}$ [28,29], respectively and other materials such as sugarcane baggase

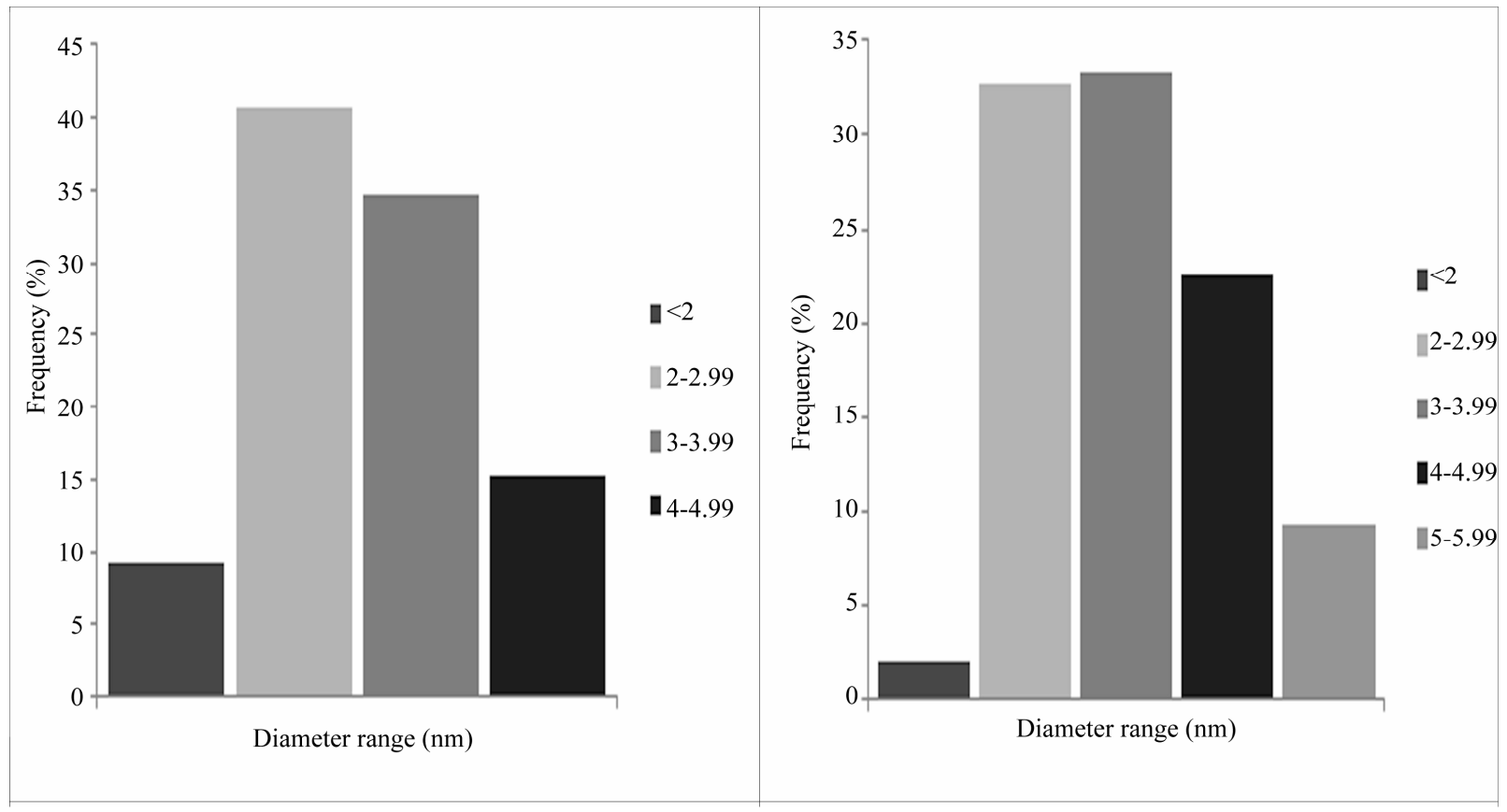

(a)

Figure 3. Size distribution of kenaf bast whiskers isolated by (a) sulfuric acid; (b) HCI hydrolysis. 
whiskers; $4 \pm 2 \mathrm{~nm}$ [14], capim dourado; $4.5 \mathrm{~nm}$ [11], and MCC; $<10 \mathrm{~nm}$ [13]. On the other hand, the whisker diameters reported by the present study are smaller than the corresponding values reported for whiskers extracted from mulberry; 20 to $40 \mathrm{~nm}$ [30], Tunicate; $10-20 \mathrm{~nm}$ and Bacterial cellulose 5 - 10 [31].

\subsection{FTIR Analysis}

Infrared spectra of kenaf bast fibers, $\mathrm{NaOH}$-treated fibers, bleached fibers, sulfuric acid whiskers, and $\mathrm{HCl}$ whiskers are displayed in Figure 4. All those spectra show a broad peak at a frequency of $3300 \mathrm{~cm}^{-1}$ which is attributed to the polysaccharides hydroxyl [32]. The C-H symmetrical stretching at $2900-2800 \mathrm{~cm}^{-1}$ indicates presence of polysaccharide [32]. The peak located at $1728 \mathrm{~cm}^{-1}$ in the spectra of kenaf fiber is related to the $\mathrm{C}=\mathrm{O}$ stretching of the acetyl groups of hemicelluloses and p-coumaric acids of lignin [33-35]. This peak was only seen in kenaf fiber, thus indicating the removal of lignin and most of the hemicellulose during the chemical treatments.

The peak appearing at $1503 \mathrm{~cm}^{-1}$ seems to indicate that lignin was not completely removed after the $\mathrm{NaOH}$ treatment. However, this peak disappeared after the bleaching treatment. This suggests that lignin was completely removed after bleaching. The peak appearing at $1610-1640 \mathrm{~cm}^{-1}$ corresponds to water absorbed in cellulose $[32,36]$. On the other hand, the peak seen at 1430 $\mathrm{cm}^{-1}$ represents the crystalline region in both whiskers while the peak seen in the range $1417-1427 \mathrm{~cm}^{-1}$ is characteristic of the $\mathrm{C}-\mathrm{H}$ bonds in all organic molecules of the other samples $[32,37]$. The intense peak observed in the $1317-1320 \mathrm{~cm}^{-1}$ region corresponds to the $\mathrm{C}-\mathrm{O}$ groups of the aromatic ring in cellulose [32].

The peaks observed at $1244 \mathrm{~cm}^{-1}$ in kenaf fiber are associated with the $\mathrm{C}-\mathrm{O}$ stretching of the aryl group in lignin [32]. This peak did not appear after the $\mathrm{NaOH}$ and bleaching treatments. The peak appearing in the 1155 $1158 \mathrm{~cm}^{-1}$ region is due to the anti-symmetrical deformation of the C-O-C band [38]. In other respects, the vibration peak detected at $898 \mathrm{~cm}^{-1}$ in the $\mathrm{NaOH}$-treated fiber and in the whiskers was linked with the $\mathrm{C}-\mathrm{H}$ outof-plane ring stretching in cellulose due to $\beta$-linkage or the glycoside bonds, which are symmetric in polysaccharides $[39,40]$.

\subsection{X-Ray Diffraction and Thermal Stability}

The X-ray diffraction and thermal properties of kenaf fiber, $\mathrm{NaOH}$-treated fiber, bleached fiber, sulfuric acid whiskers, and $\mathrm{HCl}$ whiskers are shown in Figure 5. The crystallinity index, thermal initial degradation and maximum degradation values of these materials are given in Table 1 . The crystallinity index $\left(\mathrm{C}_{\mathrm{II}}\right)$, which was calculated based on Segal's empirical method [27], can be

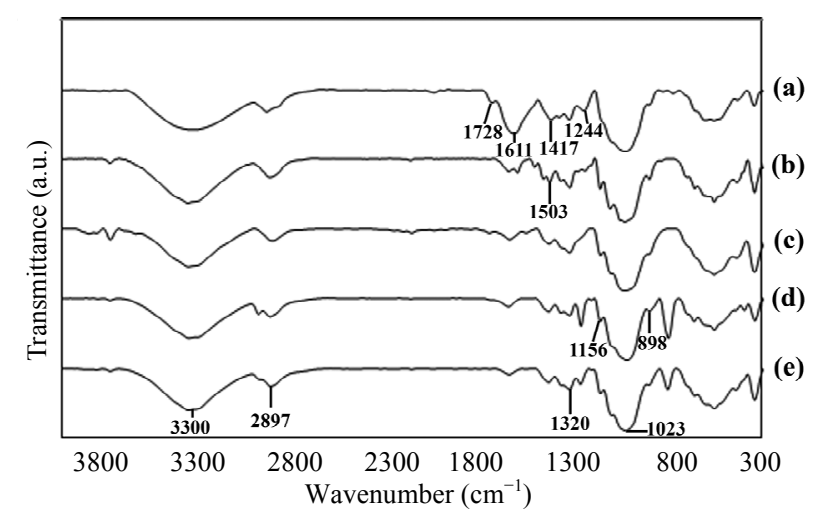

Figure 4. FTIR spectra of (a) raw bast kenaf fiber; (b) NaOH-treated fiber; (c) bleached fiber; (d) sulfuric acid whiskers; and (e) HCl whiskers.

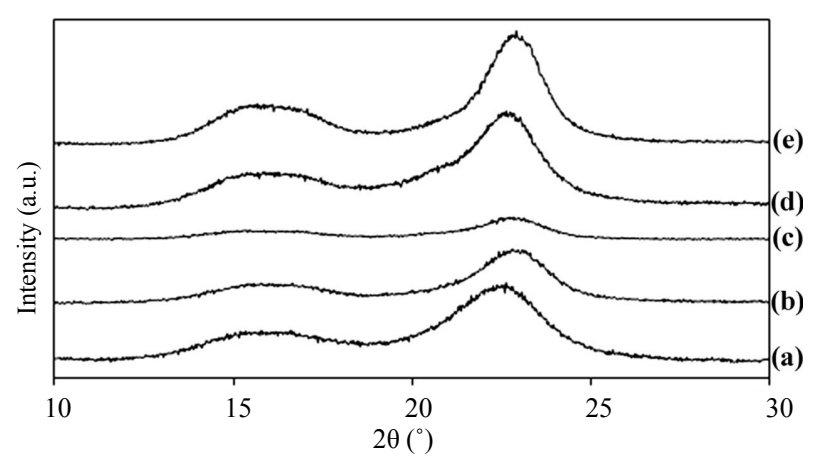

Figure 5. X-ray diffraction patterns of (a) raw bast kenaf; (b) NaOH-treated fiber; (c) bleached fiber; (d) sulfuric acid whiskers; (e) HCl whiskers.

Table 1. Crystallinity index $\left(\mathrm{C}_{I \mathrm{I} \%}\right)$ and initial degradation temperature $\left(\mathrm{T}_{\mathrm{id}}\right)$, maximum degradation temperature ( $\left.T_{\text {maxd }}\right)$ of kenaf raw fibers, $\mathrm{NaOH}$-treated fibers, bleached fibers, and whiskers from kenaf bast.

\begin{tabular}{lccc}
\hline Material & $\mathrm{C}_{\mathrm{Ir} \%}(\%)$ & $\mathrm{T}_{\mathrm{id}}\left({ }^{\circ} \mathrm{C}\right)$ & $\mathrm{T}_{\operatorname{maxd}}\left({ }^{\circ} \mathrm{C}\right)$ \\
\hline Raw bast kenaf & $67 \%$ & 177 & 321 \\
NaOH treated fibers & $77 \%$ & 256 & 368 \\
Bleached fibers & $79 \%$ & 220 & 346 \\
Sulfuric acid whiskers & $72 \%$ & 171 & 317 \\
HCl whiskers & $84 \%$ & 256 & 358 \\
\hline
\end{tabular}

used to describe the relative amount of crystalline material in fibers. The formula allow to calculate the $\%$ of crystallinity as crystalline peaks typical of cellulose I were present at around $2 \theta=18^{\circ}$ and $22.5^{\circ}$.

Kenaf fibers had $67 \%$ crystallinity which is characteristic of fibers from secondary cell wall. Furthermore, $\mathrm{NaOH}$ treatment had increased the crystallinity to $77 \%$. The increment because of the alkaline cleavage of $\beta$-Dglucopyranosides, losing a large portion of hemicellulose, and dissolution of lignin were increased the crystalline region. Fibers after the bleaching treatment also showed 
an increase in crystallinity up to $79 \%$, presumably due to the removal of remaining lignin and the intensify cleavage of cellulose molecular chain within amorphous region. Whiskers provided by sulfuric acid hydrolysis only had $72 \%$ crystallinity. Since many parameters influence the properties of whiskers such as acid concentration, time, and temperature, the low crystallinity proportion of the sulfuric acid whiskers can be related to attacking the crystalline region of the whiskers. However, the $\mathrm{HCl}$ hydrolyzed by lower acid concentration, shorter reaction time, and higher reaction temperature than sulfuric acid gave a better crystallinity index (84\%). Even though the $\mathrm{HCl}$ whiskers showed better crystallinity than the sulfuric acid whiskers, the latter had a more stable suspension. This finding is consistent with that of Araki et al. [41]. A stable suspension is important in order to achieve good dispersion of the whiskers when they are used as polymer filler.

Compared to whiskers provided from kenaf bast fiber by Khargarzadeh et al. [28] and shi et al. [29] which is had crystallinity of $81.6 \%$ and $83.9 \%$, respectively, the crystallinity in this study had a lower value. However, this result agreed with Khargarzadeh et al. [28] study that concluded decreasing value of $\mathrm{C}_{\mathrm{Ir}}$ after 40 minutes hydrolysis time.

A study of the thermal stabilities of the samples was done using TGA. This study is important since the reinforcement material has to meet minimal thermal acceptance in processing. Figure 6 shows TG and DTG curves of kenaf fibers, $\mathrm{NaOH}$-treated fibers, bleached fibers, sulfuric acid whiskers, and $\mathrm{HCl}$ whiskers. Due to evaporation of volatile material and water upon thermal treatment, the TG curve demonstrates that weight loss started from $35^{\circ} \mathrm{C}$.

The curve of kenaf fiber shows a weight loss starting at $177^{\circ} \mathrm{C}$ because of lignin were started to degrade then followed by hemicellulose at temperature around $220^{\circ} \mathrm{C}$ until finally reach its peak at $321^{\circ} \mathrm{C}$ whereas attributed to cellulose decomposition [42]. Hemicellulose is easy to degrade at low temperature $\left(220^{\circ} \mathrm{C}-315^{\circ} \mathrm{C}\right)$, while lignin degrades in a wide temperature range $\left(100^{\circ} \mathrm{C}-900^{\circ} \mathrm{C}\right)$ [42]. Besides, the $\mathrm{NaOH}$-treated fibers show the most intense peak at $368^{\circ} \mathrm{C}$ while bleached fibers and $\mathrm{HCl}$ whiskers show the peaks of highest intensity at $346^{\circ} \mathrm{C}$ and $358^{\circ} \mathrm{C}$, respectively. On the other hand, sulfuric acid whiskers show multiple peaks at $229^{\circ} \mathrm{C}$ and $317^{\circ} \mathrm{C}$. The maximum degradation temperatures were listed in Table 1. The sulfate groups introduced to the cellulose surface caused this thermal instability as manifested by multiple peaks on DTG. Lack of sulfate in the structure of $\mathrm{HCl}$ is the reason why the $\mathrm{HCl}$ whiskers show greater thermal stability than the sulfuric acid whiskers. Wang et al. [43] reported that thermal stability is higher when there is little access for the sulfate group.

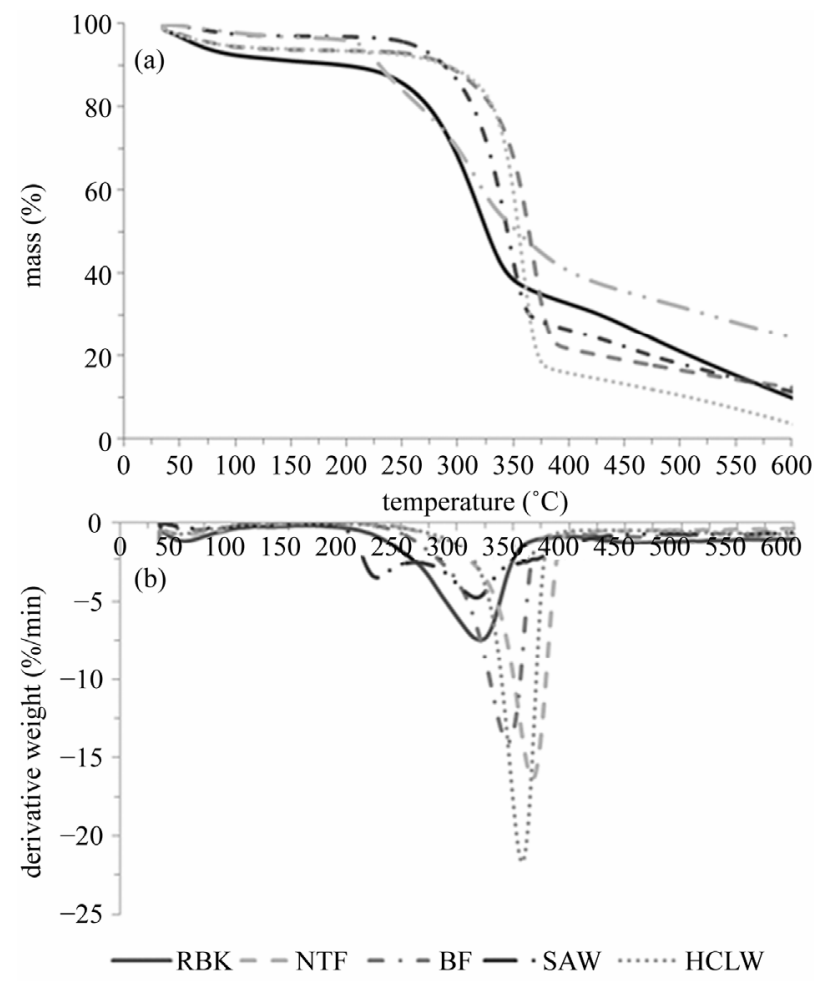

Figure 6. TG and DTG curves of raw bast kenaf, $\mathrm{NaOH}$ treated fibers, bleaching treated fibers, sulfuric acid whiskers, $\mathrm{HCl}$ whiskers.

As Table 1 reveals, the initial degradation at $171^{\circ} \mathrm{C}$ showed by sulfuric acid whiskers confirms the reduction in thermal stability of cellulose crystals due by effect of the sulfate group. The $\mathrm{NaOH}$-treated fibers, bleached kenaf fibers, and $\mathrm{HCl}$ whiskers showed initial degradations at $256^{\circ} \mathrm{C}, 220^{\circ} \mathrm{C}$, and $256^{\circ} \mathrm{C}$, respectively, presumably due to cellulose depolymerization.

\section{Conclusion}

The results of this study illustrate that hydrolysis using both sulfuric acid and $\mathrm{HCl}$ can successfully isolate whiskers from kenaf bast fibers. The sulfuric acid and $\mathrm{HCl}$ whiskers have average diameters and length range of $3 \mathrm{~nm}$ and $100-500 \mathrm{~nm}$, respectively. It is expected that a higher reinforcing capability will be possessed by the sulfuric acid, rather than the HCl-hydrolyzed whiskers. Disappearance of the peak formerly detected in the FTIR spectra at $1503 \mathrm{~cm}^{-1}$ indicates lignin removal after bleaching. Moreover, the FTIR study emphasized presence of the glycosidic bond of cellulose in both whiskers as evidenced by appearance of a peak $899 \mathrm{~cm}^{-1}$. Nevertheless, the $\mathrm{HCl}$ whiskers had better crystallinity (84\%) than the sulfuric acid whiskers $(72 \%)$. A two-stage decomposition behavior was observed upon introduction of the sulfate groups to the cellulose crystals in the sulfuric acid whiskers. A low initial degradation at $171^{\circ} \mathrm{C}$ was 
manifested by the sulfuric acid whiskers while the $\mathrm{HCl}$ whiskers showed a better thermal stability and an initial degradation temperature of $256^{\circ} \mathrm{C}$.

\section{Acknowledgements}

The authors are grateful to the Economic Planning Unit (EPU) and the Ministry of Plantation, Industry and Commodity (MPIC), the Government of Malaysia, for the financial funding of this research.

\section{REFERENCES}

[1] D. Klemm, B. Heublein, H.-P. Fink and A. Bohn, "Cellulose: Fascinating Biopolymer and Sustainable Raw Material," Angewandte Chemie International Edition, Vol. 44, No. 22, 2005, pp. 3358-3393. doi:10.1002/anie.200460587

[2] S. J. Eichhorn, et al., "Review: Current International Research into Cellulosic Fibres and Composites," Journal of Materials Science, Vol. 36, No. 9, 2001, pp. 2107-2131. doi:10.1023/A:1017512029696

[3] V. Favier, H. Chanzy and J. Y. Cavaille, "Polymer Nanocomposites Reinforced by Cellulose Whiskers," Macromolecules, Vol. 28, No. 18, 1995, pp. 6365-6367. doi: $10.1021 / \mathrm{ma} 00122 \mathrm{a} 053$

[4] P. M. Aji, A. Chakraborty, K. Oksman and M. Sain, "The Structure and Mechanical Properties of Cellulose Nanocomposites Prepared by Twin Screw Extrusion,” In: K. Oksman and M. Sain, Eds., Cellulose Nanocomposites. Processing, Characterization, and Properties, American Chemical Society, Washington DC, 2006, pp. 114-131.

[5] M. A. S. A. Samir, F. Alloin and A. Dufresne, "Review of Recent Research into Cellulosic Whiskers, Their Properties and Their Application in Nanocomposite Field," Biomacromolecules, Vol. 6, No. 2, 2005, pp. 612-626. doi:10.1021/bm0493685

[6] Y. Habibi, et al., "Bionanocomposites Based on Poly( $(\varepsilon-$ Caprolactone)-Grafted Cellulose Nanocrystals by RingOpening Polymerization," Journal of Materials Chemistry, Vol. 18, No. 41, 2008, pp. 5002-5010. doi:10.1039/b809212e

[7] J. K. Pandey, et al., "Evaluation of Morphological Architecture of Cellulose Chains in Grass during Conversion from Macro to Nano Dimensions," e-Polymers, No. 102, 2009, pp. 1618-7229.

[8] G. Siqueira, J. Bras and A. Dufresne, "Cellulose Whiskers versus Microfibrils: Influence of the Nature of the Nanoparticle and Its Surface Functionalization on the Thermal and Mechanical Properties of Nanocomposites," Biomacromolecules, Vol. 10, No. 2, 2008, pp. 425-432. doi:10.1021/bm801193d

[9] M. N. Angles and A. Dufresne, "Plasticized Starch/Tunicin Whiskers Nanocomposites. 1. Structural Analysis," Macromolecules, Vol. 33, No. 22, 2000, pp. 8344-8353. doi:10.1021/ma0008701

[10] L. Petersson and K. Oksman, "Preparation and Properties of Biopolymer-Based Nanocomposite Films Using Micro- crystalline Cellulose," In: K. Oksman and M. Sain, Eds., Cellulose Nanocomposites, Processing, Characterization and Properties, American Chemical Society, Washington DC, 2006, pp. 132-150. doi:10.1021/bk-2006-0938.ch010

[11] G. Siqueira, H. Abdillahi, J. Bras and A. Dufresne, "High Reinforcing Capability Cellulose Nanocrystals Extracted from Syngonanthus nitens (Capim Dourado)," Cellulose, Vol. 17, No. 2, 2010, pp. 289-298. doi:10.1007/s10570-009-9384-Z

[12] A. J. De Menezes, G. Siqueira, A. A. S. Curvelo and A. Dufresne, "Extrusion and Characterization of Functionalized Cellulose Whiskers Reinforced Polyethylene Nanocomposites," Polymer, Vol. 50, No. 19, 2009, pp. 4552 4563. doi:10.1016/j.polymer.2009.07.038

[13] D. Bondeson, I. Kvien and K. Oksman, "Strategies for Preparation of Cellulose Whiskers from Microcrystalline Cellulose as Reinforcement in Nanocomposites," In: K. Oksman and M. Sain, Eds., Cellulose Nanocomposites, American Chemical Society, Washington DC, 2006, pp. 10-25. doi:10.1021/bk-2006-0938.ch002

[14] E. D. M. Teixeira, et al., "Sugarcane Bagasse Whiskers: Extraction and Characterizations," Industrial Crops and Products, Vol. 33, No. 1, 2011, pp. 63-66. doi:10.1016/j.indcrop.2010.08.009

[15] G. Meshitsuka, "Utilization of Wood and Cellulose for Chemicals And Energy," In: D. N.-S. Hon and N. Shiraishi, Eds., Wood and Cellulosic Chemistry, Marcel Dekker, New York, 1991, pp. 977-1013.

[16] H. A. Krassig, "Cellulose: Structure, Accessibility, and Reactivity," Gordon and Breach Science, Yverdon, 1993.

[17] M. S. Huda, L. T. Drzal, A. K. Mohanty and M. Misra, "Effect of Fiber Surface-Treatments on the Properties of Laminated Biocomposites from Poly(Lactic Acid) (PLA) and Kenaf Fibers," Composites Science and Technology, Vol. 68, No. 2, 2008, pp. 424-432. doi:10.1016/j.compscitech.2007.06.022

[18] T. Nishino, K. Hirao, M. Kotera, K. Nakamae and H. Inagaki, "Kenaf Reinforced Biodegradable Composite," Composites Science and Technology, Vol. 63, No. 9, 2003, pp. 1281-1286. doi:10.1016/S0266-3538(03)00099-X

[19] M. Avella, et al., "Poly(Lactic Acid)-Based Biocomposites Reinforced with Kenaf Fibers," Journal of Applied Polymer Science, Vol. 108, No. 6, 2008, pp. 3542-3551. doi:10.1002/app.28004

[20] A. A. Mosello, et al., "A Review of Literatures Related to Kenaf as a Alternative for Pulpwoods," Agricultural Journal, Vol. 5, No. 3, 2010, pp. 131-138.

[21] M. Zampaloni, et al., "Kenaf Natural Fiber Reinforced Polypropylene Composites: A Discussion on Manufacturing Problems and Solutions," Composites Part A: Applied Science and Manufacturing, Vol. 38, No. 6, 2007, pp. 1569-1580. doi:10.1016/j.compositesa.2007.01.001

[22] Y. Xue, Y. Du, S. Elder, K. Wang and J. Zhang, "Temperature and Loading Rate Effects on Tensile Properties of Kenaf Bast Fiber Bundles and Composites," Composites Part B: Engineering, Vol. 40, No. 3, 2009, pp. 189196. doi:10.1016/j.compositesb.2008.11.009

[23] W. Liu, L. T. Drzal, A. K. Mohanty and M. Misra, "In- 
fluence of Processing Methods and Fiber Length on Physical Properties of Kenaf Fiber Reinforced Soy Based Biocomposites," Composites Part B: Engineering, Vol. 38, No. 3, 2007, pp. 352-359.

doi:10.1016/j.compositesb.2006.05.003

[24] M. Jonoobi, J. Harun, A. Shakeri, M. Misra and K. Oksman, "Chemical Composition, Crystallinity, and Thermal Degradation of Bleached and Unbleached Kenaf Bast (Hibiscus cannabinus) Pulp and Nanofibers," Bioresources, Vol. 4, No. 2, 2009, pp. 626-639.

[25] A. K. Mohanty, M. Misra and G. Hinrichsen, "Biofibres, Biodegradable Polymers and Biocomposites: An Overview," Macromolecular Materials and Engineering, Vol. 276-277, No. 1, 2000, pp. 1-24. doi:10.1002/(SICI)1439-2054(20000301)276:1<1::AIDMAME1>3.0.CO;2-W

[26] B. Braun, J. R. Dorgan and J. P. Chandler, "Cellulosic Nanowhiskers. Theory and Application of Light Scattering from Polydisperse Spheroids in the Rayleigh-GansDebye Regime," Biomacromolecules, Vol. 9, No. 4, 2008, pp. 1255-1263. doi:10.1021/bm7013137

[27] L. Segal, J. J. Creely, A. E. Martin and C. M. Conrad, "An Empirical Method for Estimating the Degree of Crystallinity of Native Cellulose Using the X-Ray Diffractometer," Textile Research Journal, Vol. 29, No. 10, 1959, pp. 786-794. doi:10.1177/004051755902901003

[28] H. Kargarzadeh, et al., "Effects of Hydrolysis Conditions on the Morphology, Crystallinity, and Thermal Stability of Cellulose Nanocrystals Extracted from Kenaf Bast Fibers," Cellulose, Vol. 19, No. 3, 2012, pp. 1-12.

[29] J. Shi, S. Q. Shi, H. M. Barnes and J. C. U. Pittman, "A Chemical Process for Preparing Cellulosic Fibers Hierarchically from Kenaf Bast Fibers," BioResources, Vol. 6, No. 1, 2011, pp. 879-890.

[30] R. Li, et al., "Cellulose Whiskers Extracted from Mulberry: A Novel Biomass Production," Carbohydrate Polymers, Vol. 76, No. 1, 2009, pp. 94-99. doi:10.1016/j.carbpol.2008.09.034

[31] S. Beck-Candanedo, M. Roman and D. G. Gray, "Effect of Reaction Conditions on the Properties and Behavior of Wood Cellulose Nanocrystal Suspensions," Biomacromolecules, Vol. 6, No. 2, 2005, pp. 1048-1054. doi:10.1021/bm049300p

[32] M. L. Troedec, et al., "Influence of Various Chemical Treatments on the Composition and Structure of Hemp Fibres," Composites Part A: Applied Science and Manufacturing, Vol. 39, No. 3, 2008, pp. 514-522. doi:10.1016/j.compositesa.2007.12.001

[33] J. Biagiotti, et al., "A Systematic Investigation on the Influence of the Chemical Treatment of Natural Fibers on the Properties of Their Polymer Matrix Composites,"
Polymer Composites, Vol. 25, No. 5, 2004, pp. 470-479. doi: $10.1002 /$ pc. 20040

[34] W. Liu, A. K. Mohanty, L. T. Drzal, P. Askel and M. Misra, "Effects of Alkali Treatment on the Structure, Morphology and Thermal Properties of Native Grass Fibers as Reinforcements for Polymer Matrix Composites," Journal of Materials Science, Vol. 39, No. 3, 2004, pp. 1051-1054. doi:10.1023/B:JMSC.0000012942.83614.75

[35] X. F. Sun, F. Xu, R. C. Sun, P. Fowler and M. S. Baird, "Characteristics of Degraded Cellulose Obtained from Steam-Exploded Wheat Straw," Carbohydrate Research, Vol. 340, No. 1, 2005, pp. 97-106. doi:10.1016/j.carres.2004.10.022

[36] M. K. Nacos, et al., "Kenaf xylan: A Source of Biologically Active Acidic Oligosaccharides," Carbohydrate Polymers, Vol. 66, No. 1, 2006, pp. 126-134.

[37] S. Keshk, W. Suwinarti and K. Sameshima, "Physicochemical Characterization of Different Treatment Sequences on Kenaf Bast Fiber," Carbohydrate Polymers, Vol. 65, No. 2, 2006, pp. 202-206. doi:10.1016/i.carbpol.2006.01.005

[38] M. C. Silva, et al., "Characterization of Three NonProduct Materials from a Bleached Eucalyptus Kraft Pulp Mill, in View of Valorising Them as a Source of Cellulose Fibres," Industrial Crops and Products, Vol. 27, No. 3, 2008, pp. 288-295. doi:10.1016/j.indcrop.2007.11.005

[39] M. Le Troedec, et al., "Influence of Various Chemical Treatments on the Composition and Structure of Hemp Fibres," Composites Part A: Applied Science and Manufacturing, Vol. 39, No. 3, 2008, pp. 514-522. doi:10.1016/j.compositesa.2007.12.001

[40] A. M. Adel, Z. H. Abd El-Wahab, A. A. Ibrahim and M. T. Al-Shemy, "Characterization of Microcrystalline Cellulose Prepared from Lignocellulosic Materials. Part II: Physicochemical Properties," Carbohydrate Polymers, Vol. 83, No. 2, 2011, pp. 676-687. doi:10.1016/j.carbpol.2010.08.039

[41] J. Araki, M. Wada, S. Kuga and T. Okano, "Flow Properties of Microcrystalline Cellulose Suspension Prepared by Acid Treatment of Native Cellulose," Colloids and Surfaces A: Physicochemical and Engineering Aspects, Vol. 142, No. 1, 1998, pp. 75-82. doi:10.1016/S0927-7757(98)00404-X

[42] H. Yang, R. Yan, H. Chen, D. H. Lee and C. Zheng, "Characteristics of Hemicellulose, Cellulose and Lignin Pyrolysis," Fuel, Vol. 86, No. 12-13, 2007, pp. 17811788. doi:10.1016/j.fuel.2006.12.013

[43] N. Wang, E. Ding and R. Cheng, "Thermal Degradation Behaviors of Spherical Cellulose Nanocrystals with Sulfate Groups," Polymer, Vol. 48, No. 12, 2007, pp. 3486 3493. doi:10.1016/i.polymer.2007.03.062 